\title{
The Double Dividend of Agricultural Trade Liberalization: Consistency between National Food Security and Gains from Trade
}

\author{
Nobuhiro Hosoe
}

May 2013

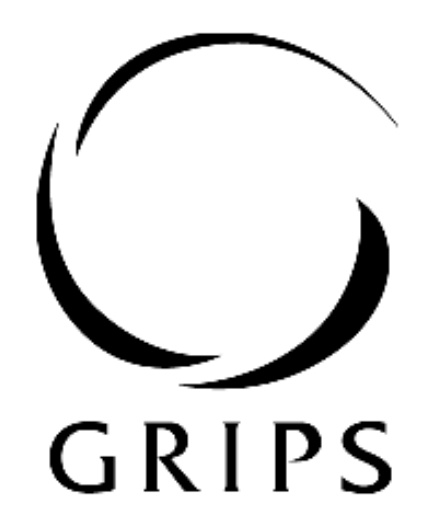

National Graduate institute

FOR POLICY STUDIES

National Graduate Institute for Policy Studies

7-22-1 Roppongi, Minato-ku,

Tokyo, Japan 106-8677 


\title{
The Double Dividend of Agricultural Trade Liberalization:
}

Consistency between National Food Security and Gains from Trade

May 7, 2013

Nobuhiro Hosoe*

National Graduate Institute for Policy Studies

\begin{abstract}
National food security is one of the main justifications used to oppose agricultural trade liberalization in Japan. Opponents of agricultural trade liberalization argue that because food supply is subject to various uncertainties, importation of cheap foods is too risky a policy. We used a Monte Carlo simulation to perform a computable general equilibrium analysis and investigated the impact of trade liberalization on national food security with random productivity shocks in four major crop markets, such as rice and wheat. Our results indicate that not only would the level of welfare be improved but also its fluctuations would be reduced by trade liberalization of rice, which shows almost perfect self-sufficiency, and by that of other crops whose supply depends heavily on importation. This double dividend would be obtained even when we focused on the cases of extremely poor crops yields.
\end{abstract}

\section{Keywords}

National food security; agricultural trade liberalization; productivity shocks; computable general equilibrium analysis; Monte Carlo simulation; double dividend

JEL Classification: Q17, Q18, D58

\footnotetext{
* Author correspondence: 7-22-1 Roppongi, Minato, Tokyo 106-8677, Japan. E-mail: nhosoe@grips.ac.jp.
} 


\section{Introduction}

While the self-sufficiency rate of rice is almost perfect, Japan heavily depends on foreign sources for supply of other major crops. The self-sufficiency rates, measured on the basis of calories, were $97 \%$ for rice, $9 \%$ for wheat, $0 \%$ for maize, and $6 \%$ for soybeans in 2010. ${ }^{1}$ The almost perfect self-sufficiency rate of rice is achieved by prohibitively high border barriers to protect the domestic rice farmers from cheap foreign rice. To resist the agricultural trade liberalization in the globalizing world economy, protectionists have often insisted on two justifications to call for exceptional treatments for rice. One is "national food security." They anticipate that the food supply could be jeopardized by the uncertainty of food production and supply in, especially, foreign countries. The other is (good) externalities by "multi-functionality of agriculture."

The relevance of the former in the rice market was examined by Tanaka and Hosoe (2011). They assumed productivity fluctuations of rice and simulated trade liberalization using a world trade computable general equilibrium (CGE) model in combination with Monte Carlo simulation, following Harris and Robinson (2001). They found that the gains from trade would significantly exceed the negative impact of bad crops in foreign countries and that Japan would suffer from rice trade liberalization as a national food security concern only if major exporters resorted to rice embargos against Japan only as often as once in several years. Maeda and Kano (2008) used a spatial partial equilibrium model and conducted similar Monte Carlo experiments to examine the effectiveness of emergency rice stocks. Rutten et al. (2013) used a GTAP-based CGE model to simulate a bad crop of wheat in Australia. They measured the effectiveness of export embargos and import tariff cuts by developing countries as measures of the reaction to the bad crop. The Science Council of Japan (2001) tried but was not able to successfully estimate the value of the externalities originating from the multi-functionality.

\footnotetext{
${ }^{1}$ Ministry of Agriculture, Forestry and Fisheries, Shokuryo Jukyu Hyo (2010) [Food Balance Sheet for 2010].
} 
Japanese supply of all crops aside from rice heavily depends on imports. Japan's wheat demand was mostly covered by North America (80\%) and Australia (20\%) in 2010. Ninety percent of maize imports and $80 \%$ of soybean imports come from North America. ${ }^{2}$ If national food security is indeed aimed at securing calorie intake in Japan, not domestic crop production, we must consider the uncertainty of supply for other major crops as seriously as we do for rice. Actually, the total calories supplied by wheat and soybeans reach 403 $\mathrm{kcal} / \mathrm{day} /$ person, which is comparable with the calories of $580 \mathrm{kcal} /$ day/person from rice. ${ }^{3}$

To justify agricultural protection to secure the food supply, we need to measure how much agricultural trade liberalization for these major crops could undermine national food security and whether the benefit of protection exceeds that of free trade. To approach this issue quantitatively, we used a world trade CGE model and applied a Monte Carlo simulation to this CGE analysis. We simulated trade liberalization of major crops by Japan subject to random productivity shocks all over the world and measured their impact on food supply and economic welfare in Japan. Our simulation results suggest that, even with productivity shocks, agricultural trade liberalization would bring about a double dividend to the Japanese economy by increasing the means of its welfare distributions and by reducing their variances. While trade liberalization of rice would bring about the largest benefit among the four major crops, the benefit of trade liberalization of wheat and maize would be also sizable.

Section 2 explains our CGE model and simulation methods. Section 3 shows our simulation results. In its first half, we examine the mean and variance of welfare distributions generated in our Monte Carlo experiments to show the consistency between agricultural trade liberalization and national food security. In the latter half of Section 3, we focus on several extremely bad crop cases among our Monte Carlo draws to verify the robustness of our conclusions. We conclude our study by discussing the implications of our

\footnotetext{
2 Japan Customs, Trade Statistics.

3 Ministry of Agriculture, Forestry and Fisheries, Food Demand and Supply Table.
} 
simulation results in Section 4. The Appendix shows the results of sensitivity analysis with respect to some key parameters in the CGE model.

\section{Model and Simulation Scenario}

\subsection{World Trade CGE Model}

We used the static world trade CGE model to analyze the impact of rice productivity shocks developed by Tanaka \& Hosoe (2011) (Figs. 2.1-2.2). In this study, we rearranged its original aggregation pattern to distinguish 10 regions, 12 sectors, and 3 primary factors so that we could make a clear comparison among the four major crop markets (Table 2.1). To describe a short-run phenomenon caused by productivity shocks, we assumed that capital, which includes farmland, was immobile among sectors. We assumed no crop stocks held by either the governments or private agents, partly to simplify the model and partly to consider a restrictive situation that would describe a severe scenario. As we focused on national food security for Japan, "grain" and "oilseed" mean maize and soybeans, respectively. As described by Hosoe et al. (2010), we calibrated the model to the data and Armington (1969) elasticity provided by GTAP Database Version 8 for 2007 (Hertel et al. (1997)). The elasticity of substitution among primary factors was assumed to be 0.2 for the agricultural sectors and 1.0 for the other seven sectors (Figure 2.1). The elasticity of substitution among agricultural goods and foods for households was assumed to be 0.1 (Figure 2.2). ${ }^{4}$

\footnotetext{
${ }^{4}$ We conduct a sensitivity analysis with respect to these elasticity parameters. Details are shown in the Appendix.
} 
Table 2.1: Aggregation of Regions, Sectors, and Primary Factors

\begin{tabular}{lclc}
\hline Region & Abbreviation & Sector & Abbreviation \\
\hline Japan & JPN & Rice* & PDR \\
Russia & RUS & Wheat* & WHT \\
EU & E_U & Grain (Maize)* & GRO \\
North America & NAM & Oilseed (Soybeans)* & OSD \\
Central and South America & LAM & Other Agriculture* & OAG \\
East Asia & EAS & Processed Rice* & PCR \\
South Asia & SAS & Vegetable Oils and Fats* & VOL \\
Southeast Asia & SEA & Other Foods* & FOD \\
Australia and New Zealand & ANZ & Oil & OIL \\
Rest of the World & ROW & Manufacturing & MAN \\
& & Transportation & TRS \\
Primary Factor & Abbreviation & Services & SRV \\
Capital & CAP & & \\
Skilled Labor & SLB & & \\
Unskilled Labor & ULB & & \\
\cline { 1 - 2 } & & &
\end{tabular}

*: Goods to be aggregated to a food composite for household consumption.

Figure 2.1: Structure of the World Trade CGE Model

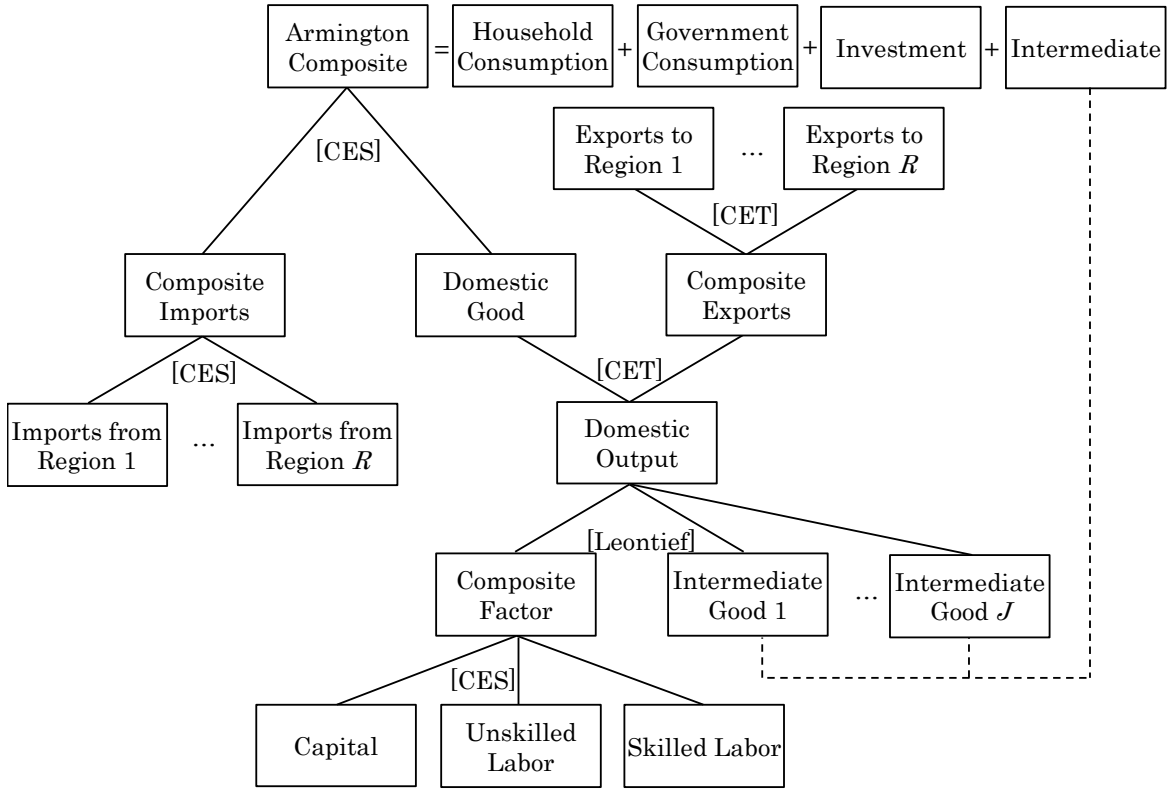

Figure 2.2: Household Consumption and Utility

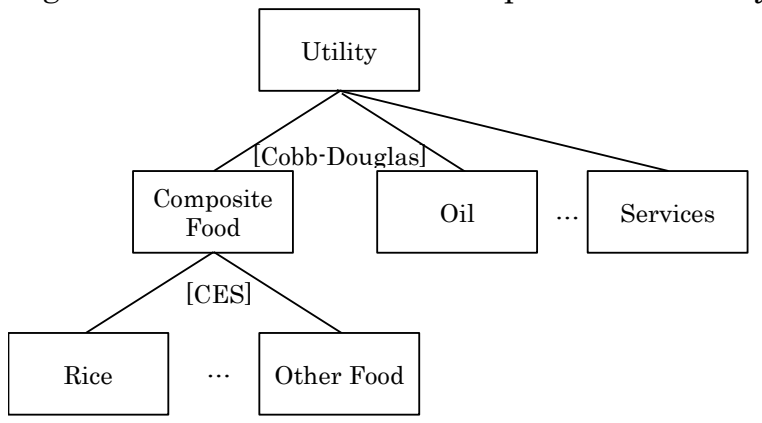


We assumed random productivity shocks for rice, wheat, grain, and oilseed. The shocks were implemented as changes in the total factor productivity in the Leontief functions in Figure 2.1. That is, agricultural output increases/decreases even with the same number of intermediates and composite factors in a good/bad crop year. The productivity shocks occur randomly; the randomness is determined by the normal distribution characterized by the standard deviations estimated for those 10 regions and four major crops with their yield data while technological progress was controlled for with a time trend variable (Table 2.2). Large standard deviations were found for grain and oilseed in Japan and all four of the crops in Australia and New Zealand. The latter may well be considered a serious risk factor for Japan's food supply, because Australia is one of the major food exporters to Japan.

Table 2.2: Standard Deviations (SD) of Productivity in the $\mathrm{r}$-th Region $\left(\sigma_{r}\right)$

\begin{tabular}{lcccc}
\hline Region & Rice & Wheat & Grain & Oilseed \\
\hline Japan & 0.079 & 0.061 & 0.129 & 0.232 \\
Russia & 0.090 & 0.102 & 0.121 & 0.083 \\
EU & 0.039 & 0.047 & 0.051 & 0.041 \\
North America & 0.032 & 0.063 & 0.051 & 0.056 \\
Central and South America & 0.031 & 0.057 & 0.037 & 0.060 \\
East Asia & 0.022 & 0.046 & 0.050 & 0.032 \\
South Asia & 0.033 & 0.027 & 0.058 & 0.069 \\
Southeast Asia & 0.014 & 0.057 & 0.025 & 0.033 \\
Australia and New Zealand & 0.120 & 0.252 & 0.194 & 0.175 \\
Rest of the World & 0.030 & 0.052 & 0.043 & 0.039 \\
\hline
\end{tabular}

Source: Author's estimates. Standard deviations of the OLS residuals of regional yield normalized to unity in 2004 using FAOSTAT for 1993-2008.

\subsection{Simulation Scenario}

We carried out Monte Carlo experiments with respect to the productivity of the four major crops in the 10 regions. We generated 1,000 draws for each scenario, assuming that productivity followed an independent, identically distributed normal distribution $N\left(1, \sigma_{r}^{2}\right)$ (Table 2.3). Some of the draws showed serious bad yields, such as a yield loss in Japan 
comparable with the actual crop shortage in 1993. Among the major exporters to Japan, the Australia and New Zealand region showed an extreme yield loss of $94 \% .{ }^{5}$ Other than those cases for Japan and Australia as well as Russia, the assumed worst crops were around 20$30 \%$ less than usual. Good crop cases showed moderate yields, too. The means and the standard deviations of the 1,000 draws generated were consistent with the original assumption as the central limit theorem predicts.

Table 2.3: Summary Statistics of Monte Carlo Draws for Productivity

\begin{tabular}{|c|c|c|c|c|c|c|c|c|c|c|c|}
\hline & & 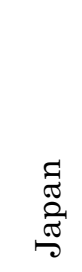 & 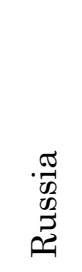 & 品 & 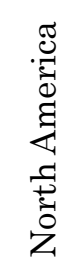 & 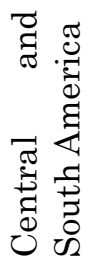 & 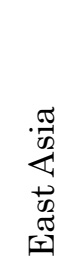 & 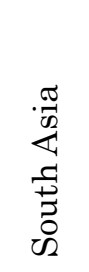 & 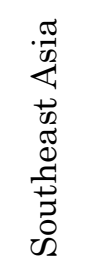 & 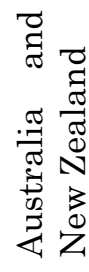 & 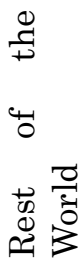 \\
\hline \multirow{4}{*}{ Rice } & Min. & 0.73 & 0.68 & 0.89 & 0.90 & 0.89 & 0.93 & 0.90 & 0.94 & 0.58 & 0.89 \\
\hline & Mean & 1.00 & 1.00 & 1.00 & 1.00 & 1.00 & 1.00 & 1.00 & 1.00 & 1.00 & 1.00 \\
\hline & Max. & 1.22 & 1.34 & 1.14 & 1.11 & 1.10 & 1.09 & 1.13 & 1.04 & 1.38 & 1.09 \\
\hline & SD & 0.08 & 0.09 & 0.04 & 0.03 & 0.03 & 0.02 & 0.03 & 0.01 & 0.12 & 0.03 \\
\hline \multirow{4}{*}{ Wheat } & Min & 0.82 & 0.70 & 0.85 & 0.82 & 0.83 & 0.82 & 0.91 & 0.78 & 0.06 & 0.86 \\
\hline & Mean & 1.00 & 1.00 & 1.00 & 1.00 & 1.00 & 1.00 & 1.00 & 1.00 & 1.00 & 1.00 \\
\hline & Max. & 1.18 & 1.29 & 1.19 & 1.18 & 1.19 & 1.16 & 1.07 & 1.16 & 1.77 & 1.17 \\
\hline & SD & 0.06 & 0.10 & 0.05 & 0.06 & 0.06 & 0.05 & 0.03 & 0.06 & 0.26 & 0.05 \\
\hline \multirow{4}{*}{ Grain } & Min. & 0.59 & 0.64 & 0.82 & 0.85 & 0.89 & 0.84 & 0.84 & 0.93 & 0.35 & 0.84 \\
\hline & Mean & 1.00 & 1.00 & 1.00 & 1.00 & 1.00 & 1.00 & 1.00 & 1.00 & 0.99 & 1.00 \\
\hline & Max. & 1.37 & 1.43 & 1.16 & 1.17 & 1.13 & 1.15 & 1.20 & 1.09 & 1.65 & 1.12 \\
\hline & SD & 0.13 & 0.13 & 0.05 & 0.05 & 0.04 & 0.05 & 0.06 & 0.02 & 0.19 & 0.04 \\
\hline \multirow{4}{*}{ Oilseed } & Min. & 0.27 & 0.74 & 0.83 & 0.82 & 0.82 & 0.88 & 0.79 & 0.89 & 0.47 & 0.88 \\
\hline & Mean & 1.00 & 1.00 & 1.00 & 1.00 & 1.00 & 1.00 & 1.00 & 1.00 & 1.00 & 1.00 \\
\hline & Max. & 1.90 & 1.28 & 1.15 & 1.22 & 1.19 & 1.09 & 1.23 & 1.10 & 1.56 & 1.12 \\
\hline & SD & 0.22 & 0.09 & 0.04 & 0.06 & 0.06 & 0.03 & 0.07 & 0.03 & 0.17 & 0.04 \\
\hline
\end{tabular}

Source: 1,000 Monte Carlo draws prepared by the author using GAMS (Brooke et al. (2012)).

We considered cases with and without unilateral agricultural trade liberalization by Japan for all crops at once and for each one of the four crops individually. For rice trade liberalization, we assumed liberalization for both paddy and processed rice. With these

\footnotetext{
${ }^{5}$ However, this case was too extreme to solve numerically when we assumed $30 \%$ larger elasticity values for sensitivity analysis. Details are shown in the Appendix.
} 
policy experiments, we measured the impact of Japan's agricultural trade liberalization on its national food security subject to uncertainty of productivity.

The trade barriers are indeed high for paddy and processed rice, but they are also high for wheat and grain (i.e., maize); their marginal impact is expected to be sizable (Table 2.4). ${ }^{6}$ In contrast, the barrier is almost zero for oilseed, and thus the impact of its liberalization is expected to be negligible. As the import dependency of these crops other than rice reaches $90 \%$ or so, Japan may gain much from further trade liberalization but be seriously affected by the impact of foreign-made shocks exacerbated by the increased import penetration. We considered the effects of these shocks and the distortions by these high trade barriers jointly to measure their combined impact in our simulations.

Table 2.4: Trade Barriers and Dependency of Foreign Food Supply in Japan

\begin{tabular}{lrrrrr}
\hline & \multicolumn{1}{c}{ Rice } & Wheat & Grain & Oilseed & Processed Rice \\
\cline { 2 - 6 } Exports from & \multicolumn{2}{c}{ Japan's Trade Barriers [Import Tariff Equivalent, \%] } \\
\hline Russia & 0.0 & 0.0 & 113.0 & 0.0 & 0.0 \\
EU & 0.0 & 67.0 & 4.0 & 0.0 & 287.0 \\
North America & 489.0 & 73.0 & 12.0 & 0.0 & 401.0 \\
Central and South America & 542.0 & 39.0 & 8.0 & 0.0 & 327.0 \\
East Asia & 589.0 & 85.0 & 15.0 & 2.0 & 490.0 \\
South Asia & 26.0 & 0.0 & 4.0 & 0.0 & 300.0 \\
Southeast Asia & 164.0 & 0.0 & 5.0 & 0.0 & 499.0 \\
Australia and New Zealand & 489.0 & 78.0 & 83.0 & 0.0 & 406.0 \\
Rest of the World & 4.0 & 5.0 & 2.0 & 0.0 & 27.0 \\
& [Share of Imports in the Domestic Consumption, \%] \\
\hline \multicolumn{7}{c}{0.4} & 86.1 & 95.0 & 88.2 & 7.9 \\
\hline
\end{tabular}

Source: Compiled by the author using the GTAP Database version 8 .

\footnotetext{
${ }^{6}$ As the trade barriers reported in the GTAP database are estimated on the basis of the price differences across borders, it is often pointed out that the estimated barriers and thus the impact of their abolition in simulations are overestimated. However, in our study, we demonstrated that none of the national food security or welfare in Japan would be undermined by the abolition of such overestimated trade barriers.
} 


\section{Simulation Results}

\subsection{Impact of Productivity Shocks on Welfare by Region}

In the first experiment, we simulated productivity shocks for all of the four major crops all over the world without unilateral agricultural trade liberalization by Japan (Scenario A0) and with it (Scenario A1) and measured their impact on Japan's welfare. Without trade liberalization, the welfare would distribute around the break-even point with a few extremely poor welfare cases (the first panel in Figure 3.1). Trade liberalization would increase the mean of the welfare distributions upward to bring deterministic gains from trade and would reduce its variance to bring stochastic gains (the second panel in Figure 3.1). That is, we can expect a double dividend from free trade. Indeed, we assumed identical shocks for these two experiments, but Scenario A1 shows no negative welfare outcome while Scenario A0 shows the above-mentioned extremely poor welfare outcome in a few cases (Table 3.1). 
Figure 3.1: Welfare Distribution with and without Trade Liberalization for All of the Four Major Crops [Equivalent Variations, mil. USD]

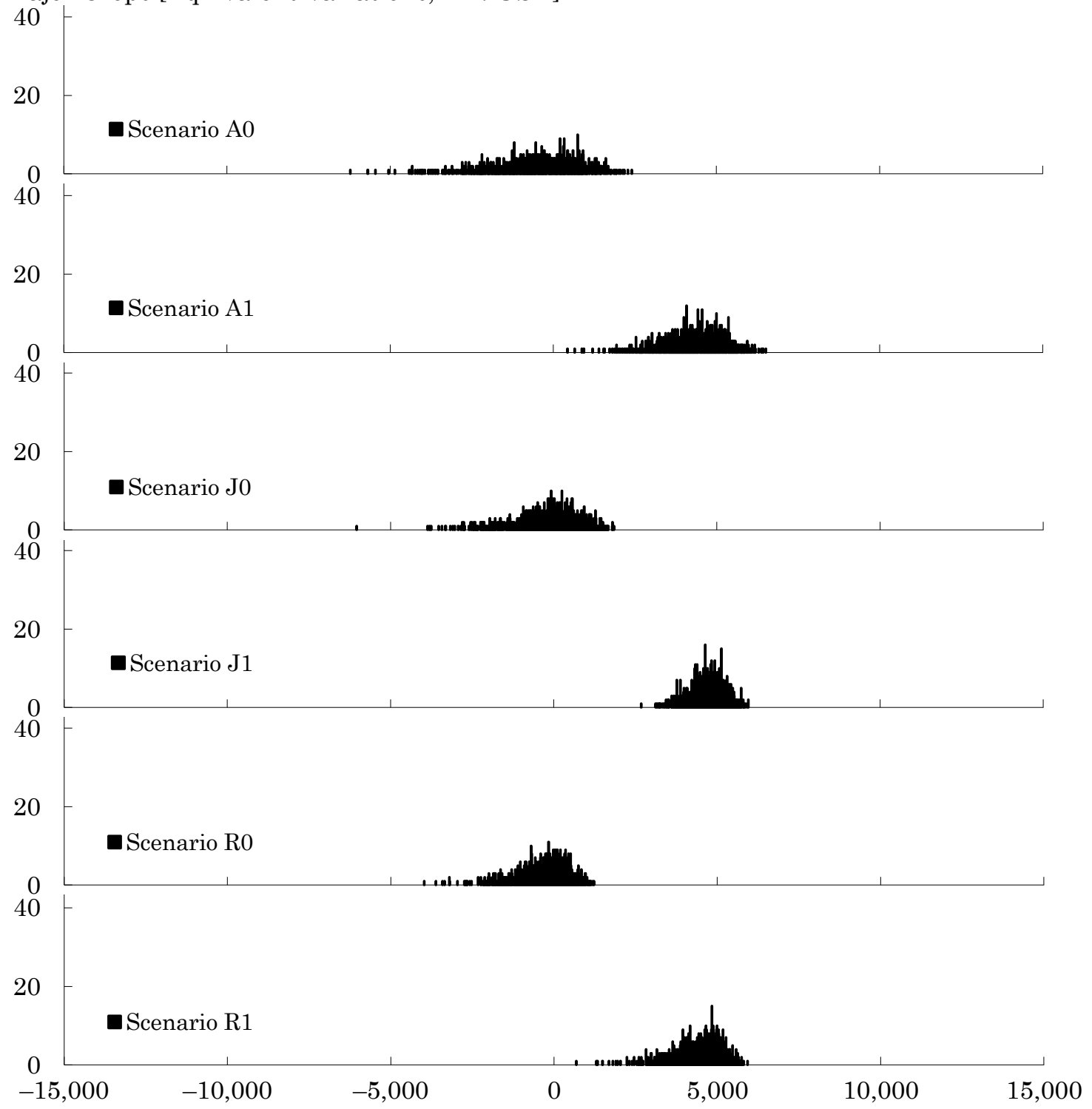


Table 3.1: Summary Statistics of the Estimated Welfare Distributions [mil. USD]

\begin{tabular}{lrrrr}
\hline Scenario & \multicolumn{1}{l}{ Min. } & \multicolumn{1}{c}{ Mean } & \multicolumn{1}{c}{ Max. } & \multicolumn{1}{c}{ SD } \\
\hline A0 & $-6,235$ & -546 & 2,396 & 1284 \\
A1 & 422 & 4,340 & 6,510 & 911 \\
J0 & $-6,045$ & -177 & 1,834 & 998 \\
J1 & 2,675 & 5,954 & 5,954 & 519 \\
R0 & $-3,980$ & -370 & 1,216 & 785 \\
R1 & 675 & 4,394 & 5,919 & 737 \\
Rice A0 & $-6,374$ & -171 & 1,775 & 990 \\
Rice A1 & 1,161 & 3,513 & 4,704 & 505 \\
Wheat A0 & $-2,697$ & -76 & 377 & 236 \\
Wheat A1 & $-1,245$ & 625 & 943 & 172 \\
Grain A0 & $-3,752$ & -258 & 1,017 & 705 \\
Grain A1 & $-3,107$ & 221 & 1,373 & 648 \\
Oilseed A0 & $-1,794$ & -46 & 714 & 329 \\
Oilseed A1 & $-1,788$ & -43 & 717 & 329 \\
\hline Soure: The autho's & & &
\end{tabular}

Source: The author's estimates.

To identify the contributions of the productivity shocks to these welfare distributions by region, we simulated the productivity shocks, first, only for Japan without trade liberalization (Scenario J0) and with it (Scenario J1), and then only for the other regions without it (Scenario R0) and with it (Scenario R1). The result of Scenario J0 shows that trade liberalization would shift the mean of the welfare distribution and would reduce its variance markedly (the fourth panel in Figure 3.1). This implies that trade liberalization would allow Japan to pool the risks across the border more flexibly.

In contrast, the result of Scenario R1 shows that although people are concerned that trade liberalization could invite risks originating from the foreign-made shocks, it would not increase the welfare variations (the sixth panel in Figure 3.1). This is partly because all the crops except rice had been almost fully supplied by foreign countries before the liberalization and partly because the anticipated productivity shocks shown in Table 2.2 are not large in the foreign regions except for Australia and New Zealand and Russia. Table 
3.1 shows that even if we anticipate productivity shocks in the foreign regions, the trade liberalization would reduce the fluctuations of welfare. That is, raising trade barriers to reduce agricultural imports and to keep the self-sufficiency rates high for these four major crops would not mitigate the negative impact of foreign-made shocks but rather make the food supply less secure.

\subsection{Impact of Productivity Shocks on Welfare by Crop}

The estimates of these deterministic and stochastic gains are dependent on crops-specific factors, such as supply capacity, household demand, and original trade barriers assumed in the base run. Here, we quantified the effects of trade liberalization for each crop by assuming their productivity shocks all over the world (Figure 3.2). The result of Scenario Rice A1, where we considered productivity shocks and trade liberalization only for rice, shows that the shift of the welfare distribution would be almost as large as that observed in Scenario A1. This indicates that the overall deterministic and stochastic gains in Scenario A1 are largely but not fully attributable to the gains from free rice trade. The gains from free rice trade are, however, only $75 \%$ of the overall gains (Table 3.1 ).

Trade liberalization for wheat and grain (maize), whose import penetration rates have already exceeded $90 \%$, would also bring about strictly positive welfare gains in terms of its larger means and smaller variations (Wheat A1, Grain A1). The gains from wheat and maize trade liberalization account for $14 \%$ and $10 \%$ of the overall welfare gains shown in Scenario A1, respectively (Table 3.1). Incidentally, as oilseed has very low trade barriers, its trade liberalization would bring about positive but negligibly small gains (Oilseed A1). 
Figure 3.2: Welfare Distribution with and without Trade Liberalization for the Four Individual Crops [Equivalent Variations, mil. USD]

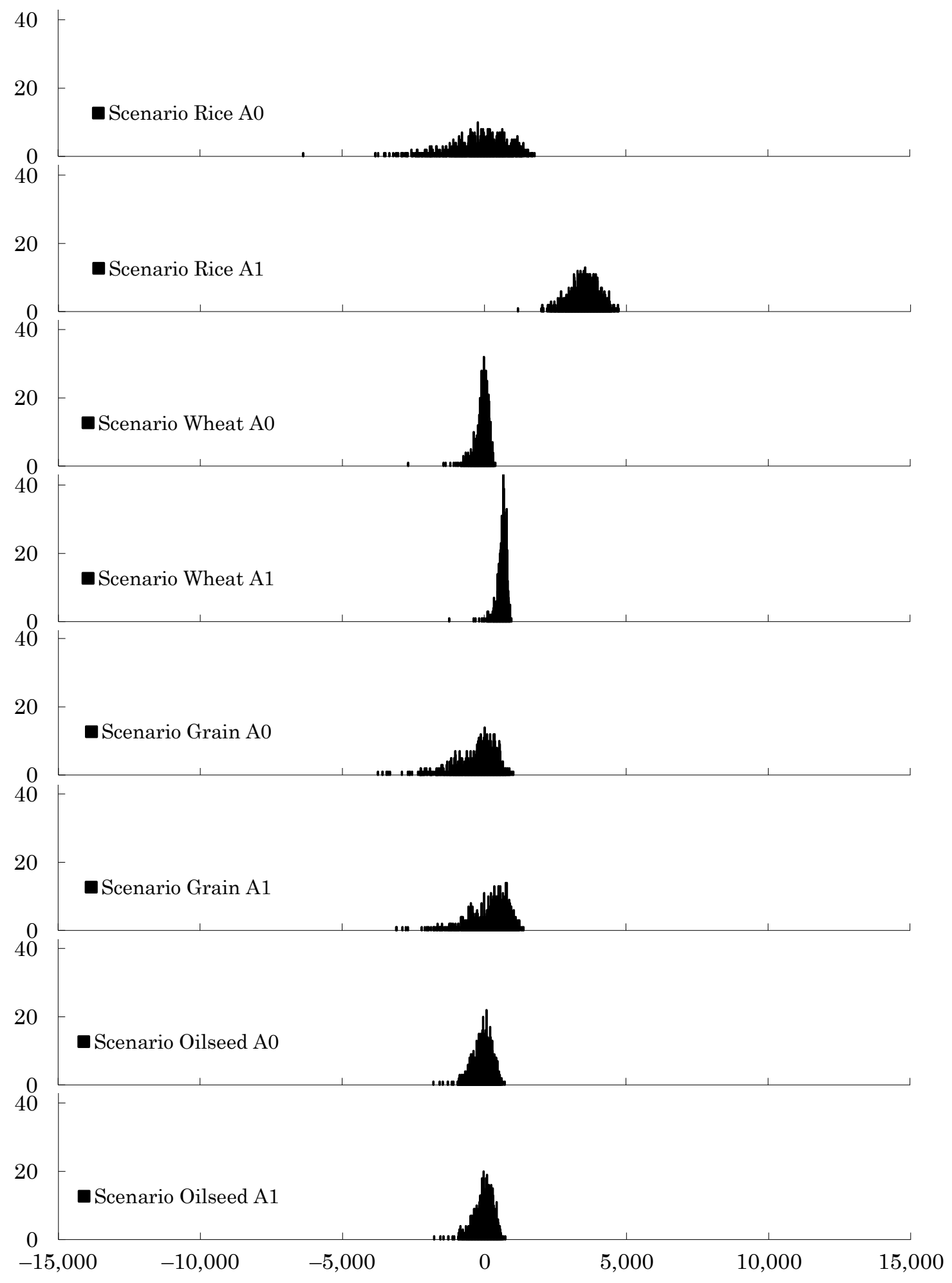




\subsection{Black Swans}

In the analysis in the previous section, we examined the means and standard deviations as summary statistics of the welfare distributions. Although we found agricultural trade liberalization had a preferable welfare impact overall, some rare but extremely bad crop cases may be considered too adverse for trade liberalization to be accepted as a reasonable policy option. Therefore, we scrutinized the results of such extremely bad crop cases, or so-called "black swans," individually.

As rice is almost fully supplied by domestic producers in Japan, we focused on the case with the worst productivity shock in Japan (Scenario Rice W) (Table 3.1). (As for the other agricultural products, we did not assume any trade liberalization or productivity shocks at all.) In contrast, wheat, maize, and soybeans are almost completely supplied by foreign countries. Thus, we focused on the worst case for wheat in North America (Scenario Wheat W(NAM)) and that in Australia and New Zealand (Scenario Wheat W(ANZ)). For grain (maize) and oilseed (soybean), we focused on their worst yield cases in North America (Scenarios Grain W and Oilseed W).

Table 3.1: Productivity Shocks and Simulation Results in the Black Swan Scenarios

\begin{tabular}{|c|c|c|c|c|c|c|c|c|}
\hline \multirow[b]{2}{*}{ Scenario } & \multicolumn{3}{|c|}{ Productivity Shocks 1 [\%] } & \multirow[b]{2}{*}{$\begin{array}{c}\text { Welfare }^{/ 2} \\
\text { [mil. USD] }\end{array}$} & \multicolumn{4}{|c|}{ Consumption ${ }^{2}[\%]$} \\
\hline & Japan & $\begin{array}{c}\text { North } \\
\text { America }\end{array}$ & $\begin{array}{l}\text { Australia } \\
\text { and New } \\
\text { Zealand }\end{array}$ & & $\begin{array}{c}\text { Processed } \\
\text { Rice }\end{array}$ & Wheat & Grain & Oilseed \\
\hline Rice W & -27.5 & -3.1 & -5.3 & 7,535 & 15.3 & 4.6 & 4.6 & 4.6 \\
\hline Wheat W(NAM) & -3.6 & -17.7 & -2.5 & 748 & 0.1 & 5.5 & 0.2 & 0.2 \\
\hline Wheat W(ANZ) & -6.4 & -11.0 & -94.4 & 1,452 & 0.3 & 5.9 & 0.3 & 0.3 \\
\hline Grain W & 3.3 & -14.7 & -3.7 & 820 & 0.1 & 0.2 & 1.6 & 0.2 \\
\hline Oilseed W & -7.0 & -17.5 & 52.9 & 5 & 0.0 & 0.0 & 0.0 & 0.0 \\
\hline
\end{tabular}

Note: /1 Productivity shocks other than these three regions are not shown but also considered here. $/ 2$ The improvements achieved in the free trade case compared with the case without trade liberalization.

The results of the worst case scenarios show that even if the productivity of rice in 
Japan declined as seriously as it did in 1993, rice trade liberalization itself would improve the country's welfare and increase rice consumption by $15 \%$ compared to the case without rice trade liberalization. Additionally, the gains from trade in this worst-case scenario would be twice as large as the average gains (i.e., 3,684 mil. USD) shown in Table 3.1. This is because the bad rice crop makes the value of rice appreciate and consequently increases the gains from rice trade. In the cases with the worst wheat crops in the foreign regions, free wheat trade would also bring about strictly positive gains and would increase wheat consumption by about $6 \%$. Similar findings can be made in Scenario Grain W. In Scenario Oilseed W, the impact of its trade liberalization would be negligible but positive because it currently has low trade barriers.

\subsection{Households Losing Agricultural Income}

Agricultural trade liberalization benefits non-farm households but adversely affects farm households that have been protected with high trade barriers. In our analysis, however, we assumed a representative household in each region for simplicity and could not distinguish these two types from each other. To complement this shortcoming of our macroeconomic CGE analysis, we used household survey data to examine the micro-impact of agricultural trade liberalization on income of general households by domestic sub-regions and income deciles with National Survey of Family Income and Expenditure (NSFIE) as well as that of farm households with Agricultural Business Survey (ABS), especially for rice farmers. ${ }^{7}$

For general households, agricultural income (though not just from rice farming) has a very small share in all the 47 prefectures in Japan (Figure 3.3). This figure, where

\footnotetext{
${ }^{7}$ For simplicity, we used data only for households with two or more family members reported in NSFIE (48,356 samples) and omitted data for single-member households (3,993 samples). As for farm households, we used data only for self-employed farmers in ABS (1,624 samples) but omitted data for farmers running farming companies (191 samples).
} 
prefectures with a larger share of rice production in the total prefectural agricultural production are ordered from the left, does not indicate conspicuous positive correlation between the large presence of rice farming and high agricultural income. Contrary to this expectation, prefectures with relatively large agricultural income composition often have a small rice farming presence (e.g., Saga, Tottori, Aomori, Kumamoto, Wakayama, Miyazaki, Kagoshima). Therefore, rice trade liberalization can hardly be anticipated to adversely affect the major rice-producing prefectures. Similarly, as little correlation between the agricultural income and income level is observed in Figure 3.4, rice trade liberalization is not anticipated to have an adverse impact on specific income groups.

Figure 3.3: Income Composition by Prefecture [\%]

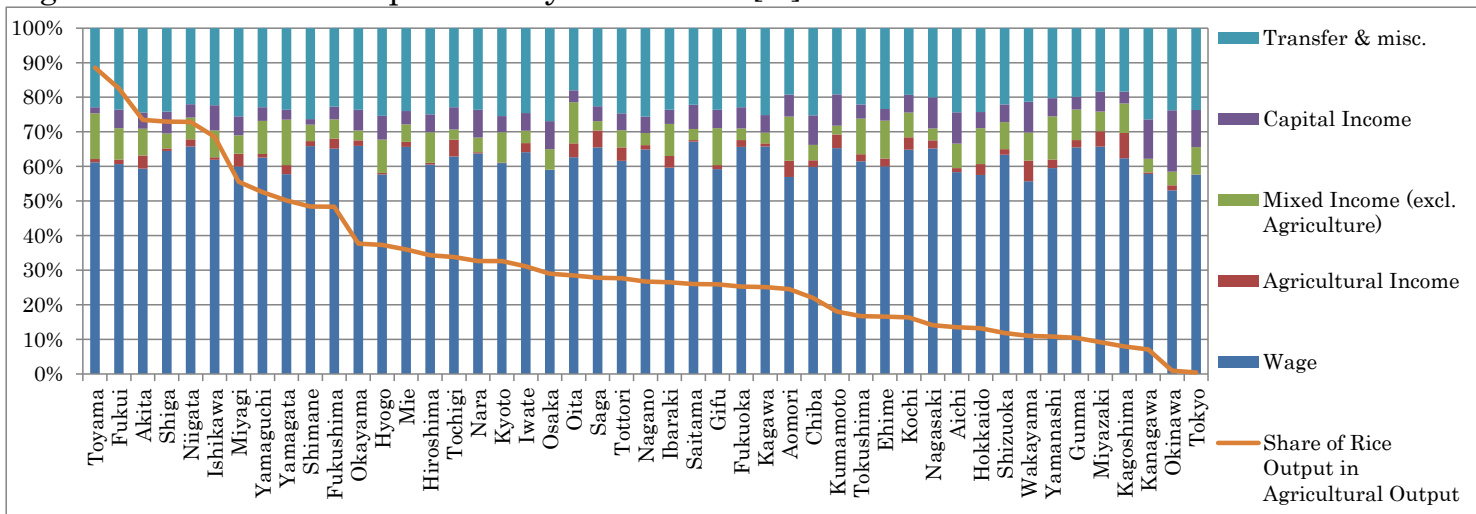

Source: Annual income composition is computed based on the made-to-order aggregation of income data of households with multiple family members by the NSFIE for 2009. The share of rice output in total prefectural agricultural output is computed with data by Agricultural Production and Income Survey for 2009. 
Figure 3.4: Income Composition by Income Decile [\%]

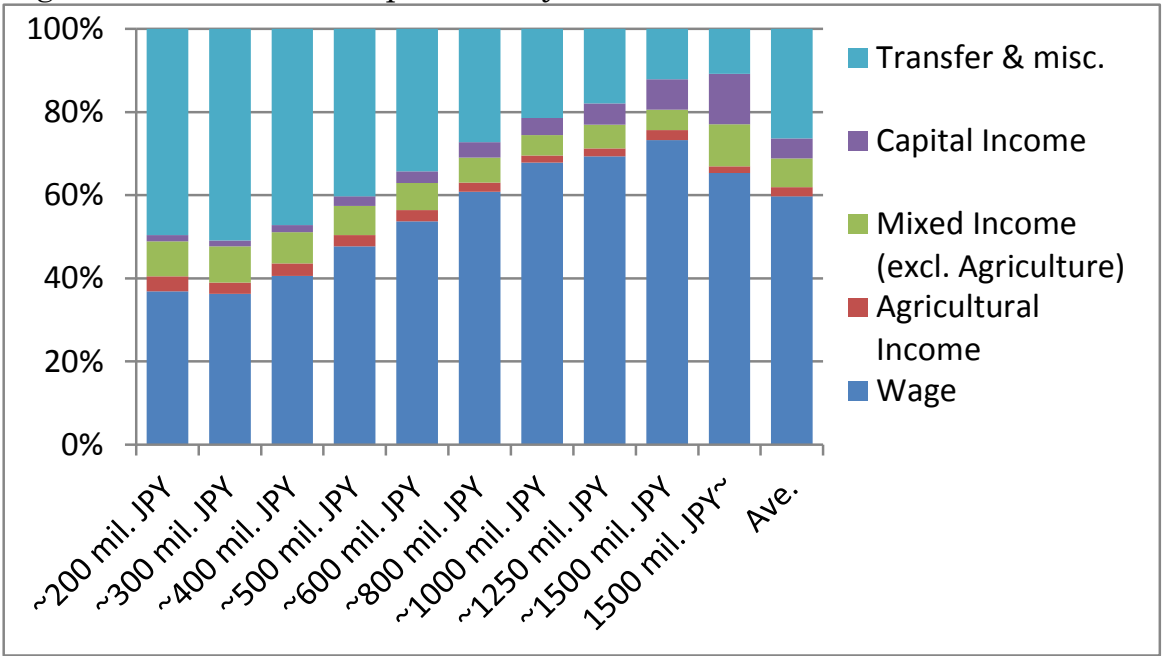

Source: Annual income composition is computed based on the made-to-order aggregation of income data of households with multiple family members in the NSFIE for 2009.

Because the above-mentioned examinations were made with data covering both farm and non-farm households, a different picture was obtained when we focused on the latter group. For example, rice-farmers with planted acreage smaller than 3.0 hectares earn mostly from non-agricultural activities or transfers such as a pension (Figure 3.5). The adverse impact of rice trade liberalization would not be significant for such small-scale farmers that do rice-farming on the side. If the adverse impact is considerable for them, they will quit farming so as not to take losses from rice-farming. Thus, ignoring problems such as externalities of abandoned paddy fields and vanishing rural communities, their maximum pecuniary losses would be as much as they earn from rice-farming before rice trade liberalization. Even while being strictly protected by high trade barriers, small-scale farmers with 0.5 hectares of planted acreage are in the red (Figure 3.6). ${ }^{8}$ As the simulation results shown in Section 3.1 indicate that production and price of rice would decrease by $35 \%$ on average, let us simply cut the agricultural sales of rice shown in Figure 3.5 by $35 \%-$

8 Godo (2006) explained that this seemingly irrational business management of farmers was supported by their expected profits from diverting paddy fields to housing and factory lots as well as expropriation for road construction. They can enjoy various tax benefits for farmland applied until its diversion or expropriation. 
assuming only rice prices would decline by that much without any change of output. In this case, small-scale farmers with 3.0 hectares of planted acreage would go into debt (Figure 3.7).

Figure 3.5: Farm Size Composition by Planted Acreage [\%] and Before-tax Annual Income [thousand JPY, right axis]

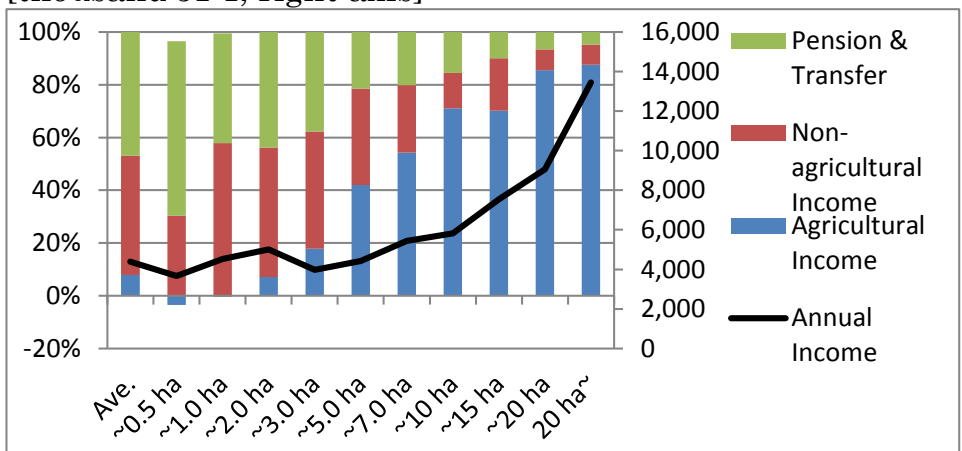

Source: Data for Self-employed rice farmers in ABS for 2009. The agricultural income includes income from agriculture-related businesses.

Figure 3.6: Agricultural Sales and Costs by Planted Acreage [thousand JPY]

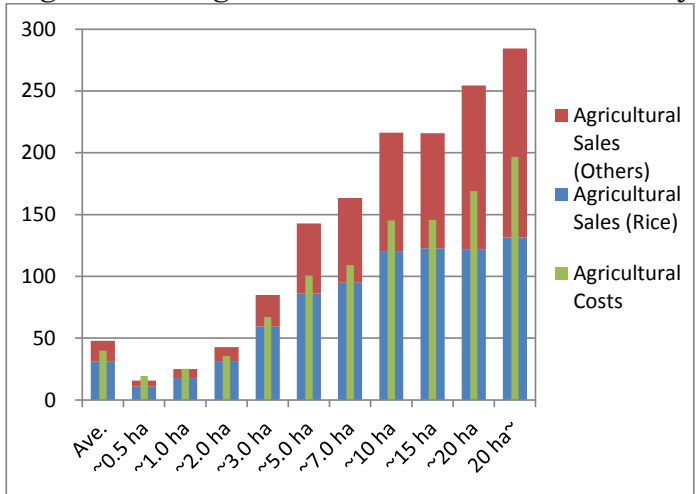

Source: Same as Figure 3.5.

Figure 3.7: Simulated Agricultural Sales and Costs by Planted Acreage [thousand JPY]

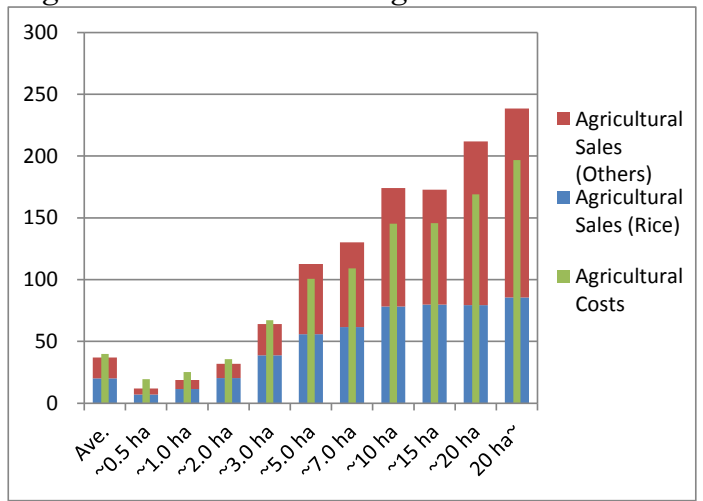

Source: Same as Figure 3.5. The agricultural sales of rice were assumed to be cut by $35 \%$. 
As discussed above, the decline of rice production would primarily hit smaller-scale farmers, who are likely to be less profitable. Rice farmers with less than 10 hectares of planted acreage produce about $30 \%$ of total rice production. Assuming they quit rice-farming, the production of larger-scale farmers is affected little (Figure 3.8). ${ }^{9}$ The rice price fall would also affect large-scale farmers adversely but not so severely because they earn only half of their income from rice-farming (Figure 3.6). Moreover, larger farmers tend to earn more from non-rice-farming. They can expand their businesses by acquiring farmland released by those small-scale farmers who quit farming and partially cancel out the rice price falls with general price falls of farming materials thanks to the trade liberalization.

Figure 3.8: Distribution of Cumulative Share of Rice Farmers and Planted Acreage [\%]

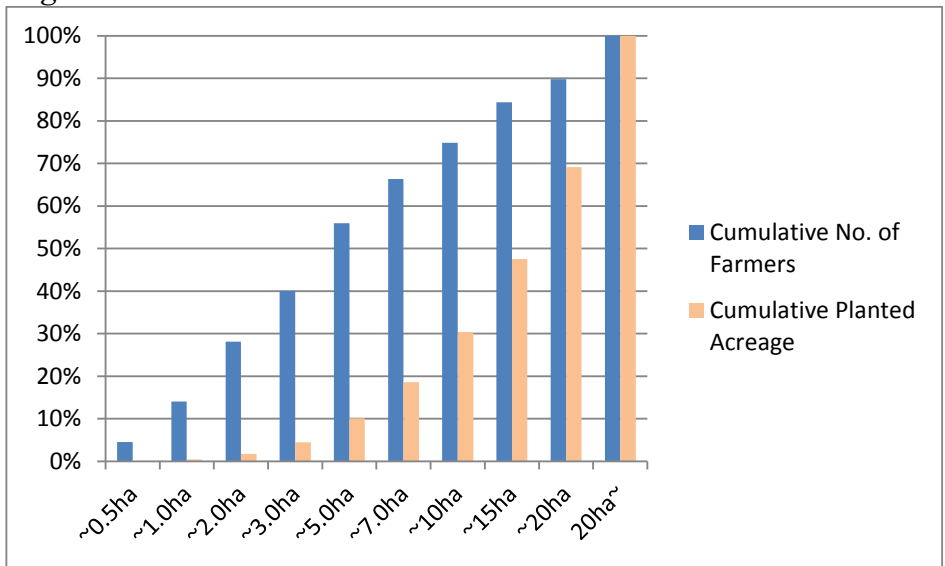

Source: Compiled by the author with ABS for 2009. Class means of planted acreage (but 20 hectares for the largest class) are used to compute the distribution.

\section{Conclusion}

We conducted Monte Carlo experiments with a world trade CGE model to examine the impact of uncertainty of food supply, on which the concern of Japan's national food security is based. Assuming productivity shocks of four major crops all over the world and

\footnotetext{
9 However, as noted in footnote 7, we omitted data for very large-scale farmers in our analysis. Thus, larger-scale farmers may be forced by trade liberalization to reduce their output.
} 
simulating their trade liberalization by Japan, we quantified the contribution of agricultural free trade to securing the supply of these four major crops for Japan. We found that the trade liberalization would bring about not only deterministic gains from trade, which is often predicted by the conventional trade theory, and that these gains would be considerable not only in trade liberalization of rice but also in trade liberalization of wheat and maize, as very high trade barriers are set on these three crops. Additionally, we found that agricultural trade liberalization would bring about stochastic gains from trade by integrating the domestic market with foreign markets and pooling the risks originating from uncertainty of crop yields in these markets. Even if we anticipated extremely bad crops in the major crop-exporting regions to Japan, such as North America, and Australia and New Zealand, agricultural trade liberalization would not only shift the means of Japan's welfare distributions but, notably, would protect Japan from suffering a negative welfare impact.

We used a Monte Carlo method when we assumed a normal distribution to randomly generate productivity shocks so as not to arbitrarily assume the signs and magnitude of shocks-although the choice of the normal distribution was indeed our own a priori assumption. Alternatively, we can assume other parameter values for the normal distribution and/or other types of distribution to simulate uncertainty of yields. We can demonstrate more disastrous situations that people should more seriously prepare for. However, we should take note that more disastrous situations occur less frequently, as Tanaka and Hosoe (2011) discussed. 


\section{Acknowledgements}

The author gratefully acknowledges Masaru Kagatsume, Tetsuji Tanaka, and the seminar participants at the Japan International Research Center for Agricultural Sciences for their helpful suggestions. This work is supported by JSPS KAKENHI Grant (No. 21730222, 25380285), Tokyo Center of Economic Research, and Policy Research Center of GRIPS. This study is made with a made-to-order statistical product produced on the basis of the statistics law with National Survey of Family Income and Expenditure issued by Statistics Bureau, Ministry of Internal Affairs and Communications, Government of Japan. The usual disclaimer applies.

\section{References}

Armington, P. (1969) "A Theory of Demand for Products Distinguished by Place of Production,” IMF Staff Papers 16 (1): 159-178.

Brooke, A., Kendrick, D., Meeraus, A., Raman, R. (2012) GAMS-A User's Guide, GAMS Development Corporation, Washington, DC.

Furuya, J., Koyama, O. (2005) "Impacts of Climatic Change on World Agricultural Product Markets: Estimation of Macro Yield Functions," Japan Agricultural Research Quarterly 39(2): 121-134.

Godo, Y. (2006) Nippon-no Shoku-to-Nou: Kiki-no Honshitsu [Japan's Food and Agriculture: the Real Nature of their Crisis], NTT Publishing (in Japanese).

Maeda, K., Kano, H. (2008) "Kokusai-kome-bichiku-ni-yoru Shokuryo-anzen-hosho-to shijo-anteika-Kukan-kinko-moderu-ni-yoru Keiryo-bunseki [Food Security and Market Stabilization through International Rice Reserve Stock: A Spatial Equilibrium Analysis]," Nogyo-keizai-kenkyu [Journal of Rural Economics] 79 (4): 199-216 (in Japanese).

Ministry of Agriculture, Forestry and Fisheries, Nogyo Keiei Tokei Chosa [Agricultural Business Survey], Self-employed Farmers in 2009, Government of Japan, Tokyo. 
<http://www.e-stat.go.jp/SG1/estat/List.do?lid=000001072789>

February 6, 2013).

Ministry of Agriculture, Forestry and Fisheries, Seisan Nogyo Shotoku Tokei [Agricultural Production and Income Survey], Government of Japan, Tokyo. $<$ http://www.e-stat.go.jp/SG1/estat/List.do?lid=000001084169> (Accessed on February 6, 2013).

Ministry of Agriculture, Forestry and Fisheries, Shokuryo Jukyu Hyo [Food Balance Sheet], Government of Japan, Tokyo.

$<$ http://www.maff.go.jp/j/zyukyu/fbs/pdf/2-5-1-1.pdf> (Accessed on March 12, 2012).

Harris, R. L., Robinson, S. (2001) "Economy-wide Effects of El Niño/Southern Oscillation (ENSO) in Mexico and the Role of Improved Forecasting and Technological Change," TMD Discussion Paper No. 83, International Food Policy Research Institute, Washington, DC.

Hertel, T. W. (ed.) (1997) Global Trade Analysis, Cambridge University Press, Cambridge.

Hosoe, N., Gasawa, K., Hashimoto, H. (2010) Textbook of Computable General Equilibrium Modeling, Palgrave Macmillan.

Japan Customs, Trade Statistics, Ministry of Finance, Government of Japan, Tokyo. <http://www.customs.go.jp/toukei/srch/index.htm> (Accessed on March 12, 2012).

Rutten, M., Shutes, L., Meijerink, G. (2013) "Sit Down at the Ball Game: How Trade Barriers Make the World Less Food Secure," Food Policy 38: 1-10.

Science Council of Japan (2001) "Chikyu-kankyo Ningen-seikatsu-ni-kakawaru Nogyo-oyobi-shinrin־no Tamenteki-na-kino-no Hyoka-ni-tsuite (Toshin) [Report on the Multi-functionality of Agriculture and Forest for Global Environment and Human Life],” November, Tokyo (in Japanese).

Statistics Bureau, National Survey of Family Income and Expenditure (NSFIE) for 2009, made-to-order aggregation, Ministry of Internal Affairs and Communication, Government of Japan, Tokyo. 
Tanaka, T., Hosoe, N. (2011) "Does Agricultural Trade Liberalization Increase Risks of Supply-side Uncertainty?: Effects of Productivity Shocks and Export Restrictions on Welfare and Food Supply in Japan," Food Policy 36(3): 368-377. 


\section{Appendix Sensitivity Analysis}

The results presented in the main text are dependent on many assumptions of our own. One crucial assumption was made for the elasticity of substitution used in the CES/CET functions (Figures 2.1-2.2). We examined robustness of our simulation results by perturbing the elasticity values in various ways. We assumed four alternative cases: $30 \%$ larger or smaller values for the Armington elasticity, 1.0 for the elasticity of substitution among agricultural goods and foods, and 1.0 for that among primary factors used in the agricultural sectors. Second, we verified the validity of our assumption for the spatial correlations of crop productivity shocks by examining their correlation matrices.

\section{A.1 Sensitivity Analysis with Respect to Elasticity of Substitution}

When we assumed a larger Armington elasticity, people could more flexibly substitute domestic goods with foreign goods and, thus, would gain more from trade. This is shown by the larger rightward shift of the welfare distributions (Figures A.1-A.4) than the shift shown in the main text (Figures 3.1-3.2). This large flexibility also would allow people to manage the impact of uncertainty better as well. This is shown by the smaller variations of welfare in these figures. When we examined the other alternative cases with larger elasticity of substitution among agricultural goods and foods (Figures A.4-A.6) and that among primary factor input (Figure A.7-A.8), we found our conclusion robust that agricultural trade liberalization would benefit Japan in terms of its welfare level and certainty.

Incidentally, we included one extreme case indicating a huge decline of wheat productivity by $94.4 \%$ in Australia and New Zealand among the 1,000 Monte Carlo draws. ${ }^{10}$ This case causes computational infeasibility in our numerical simulations only when we

10 We used the normal function equipped in GAMS (Brooke et al. (2012)) with "Option Seed=1" to generate the random draws with the mean of 1.0 and the standard deviations shown in Table 2.2. 
assumed 30\% larger Armington elasticity to examine six scenarios: A0, A1, R0, R1, Wheat A0, and Wheat A1. In these cases, we assumed a $97 \%$ smaller shock than the original draw (i.e., a 91.5\% decline) for the wheat productivity in Australia and New Zealand) to avoid the numerical infeasibility. Thus, the results shown in Figure A.1-A.2 include one case with this modified draw.

While we assumed only capital, which includes all the primary factors but labor in our aggregation based on the GTAP database, was immobile among sectors, we can alternatively assume that all are inter-sectorally mobile. This alternative assumption would provide people with more flexibility in their adjustments to the shocks (whether they are preferable or adverse) and would generate welfare distributions with larger means and smaller standard deviations to reinforce the robustness of our finding. 
Figure A.1: Welfare Distribution with and without Trade Liberalization for All of the Four Major Crops (30\% Larger Armington Elasticity Case) [mil. USD]

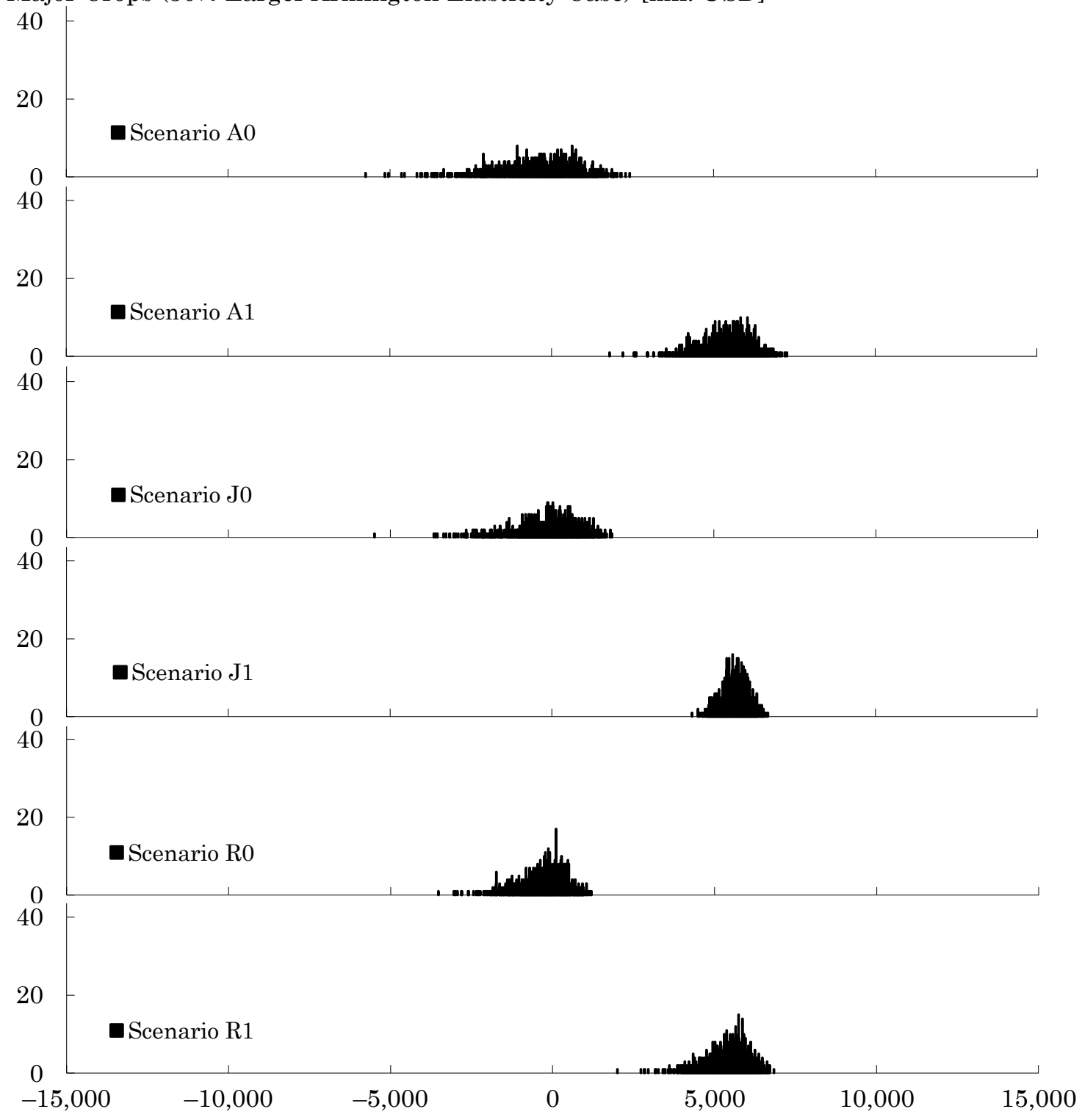


Figure A.2: Welfare Distribution with and without Trade Liberalization for the Four Individual Crops (30\% Larger Armington Elasticity Case) [mil. USD]

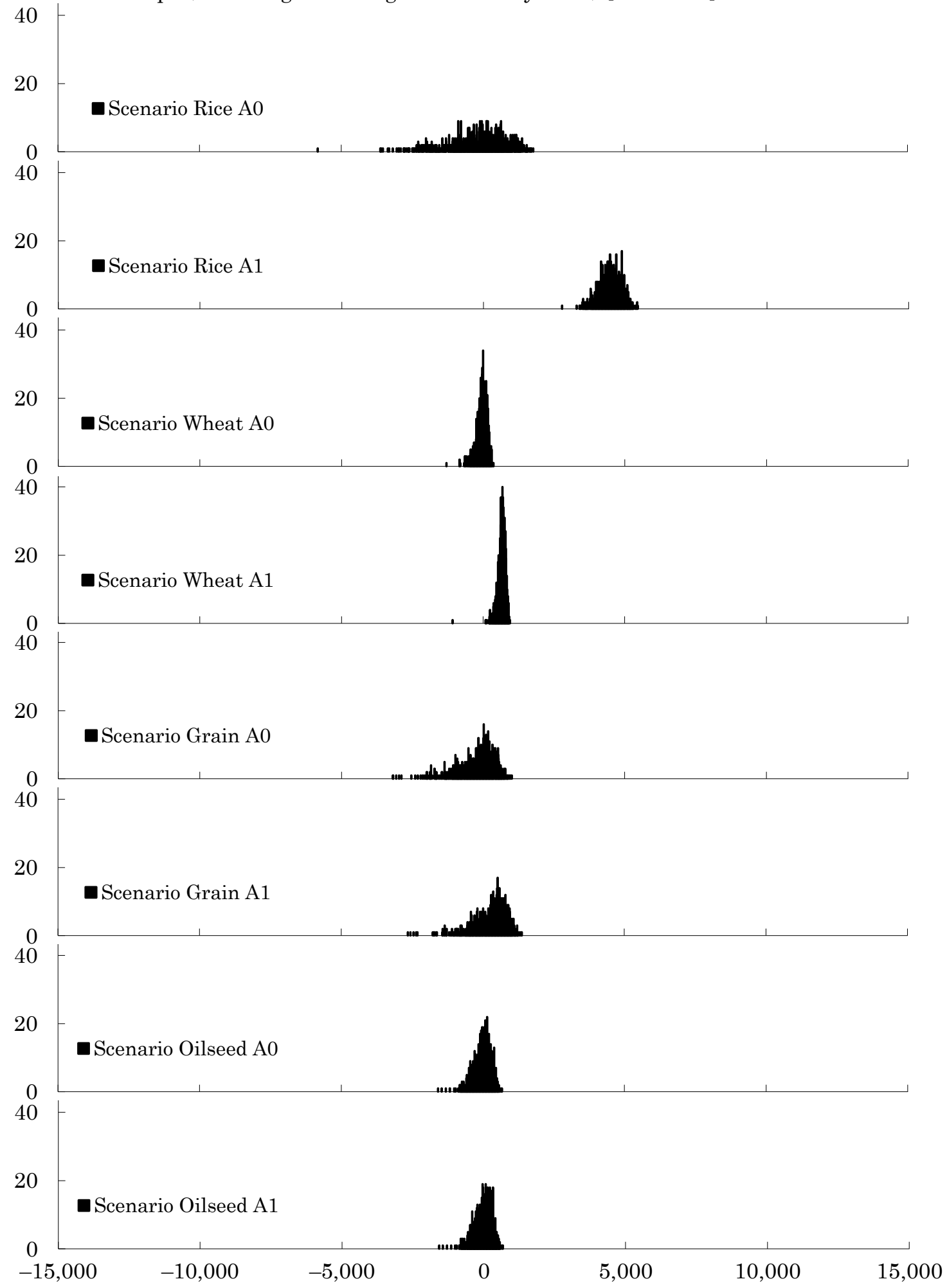


Figure A.3: Welfare Distribution with and without Trade Liberalization for All of the Four Major Crops (30\% Smaller Armington Elasticity Case) [mil. USD]

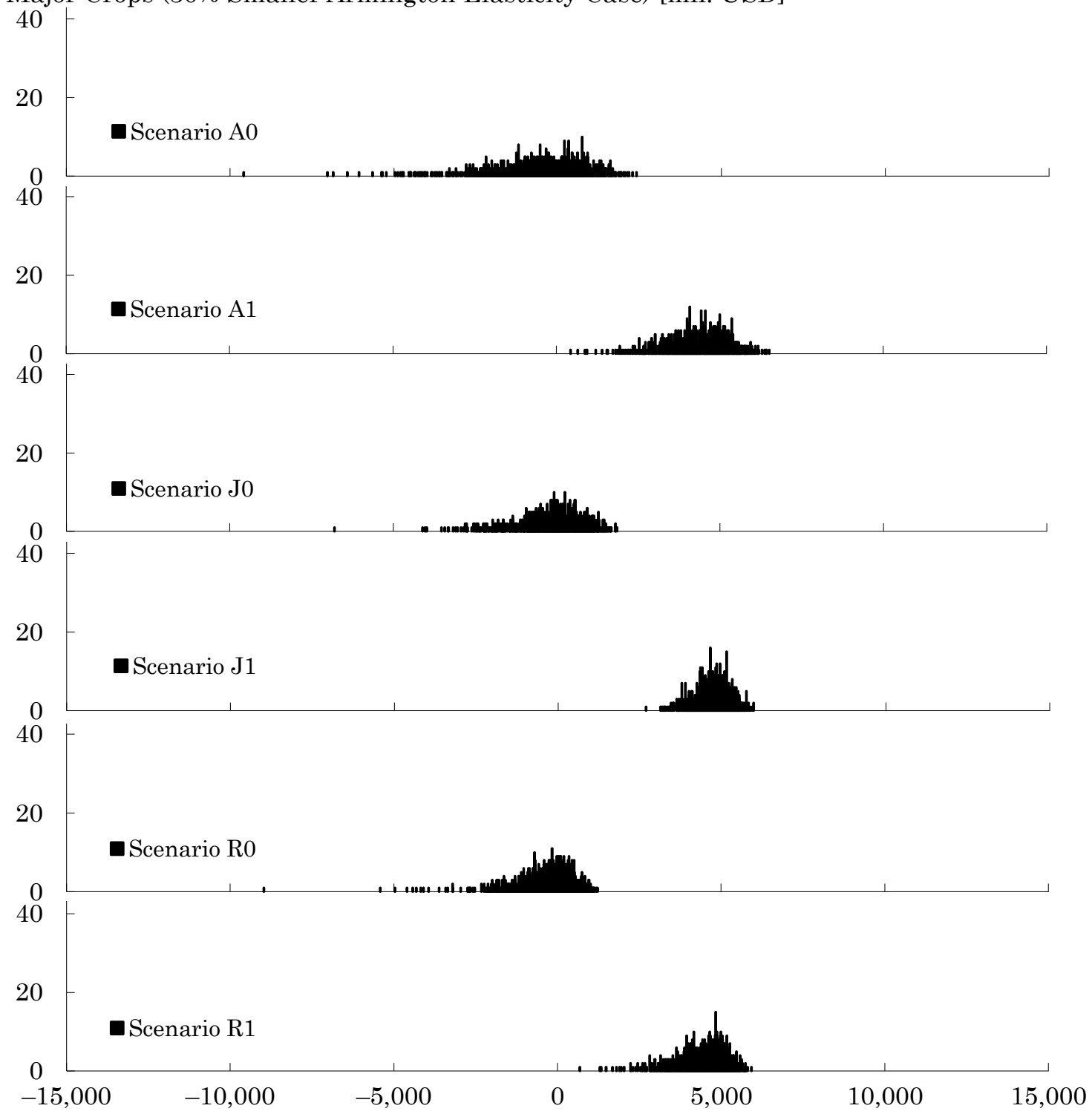


Figure A.4: Welfare Distribution with and without Trade Liberalization for the Four Individual Crops (30\% Smaller Armington Elasticity Case) [mil. USD]

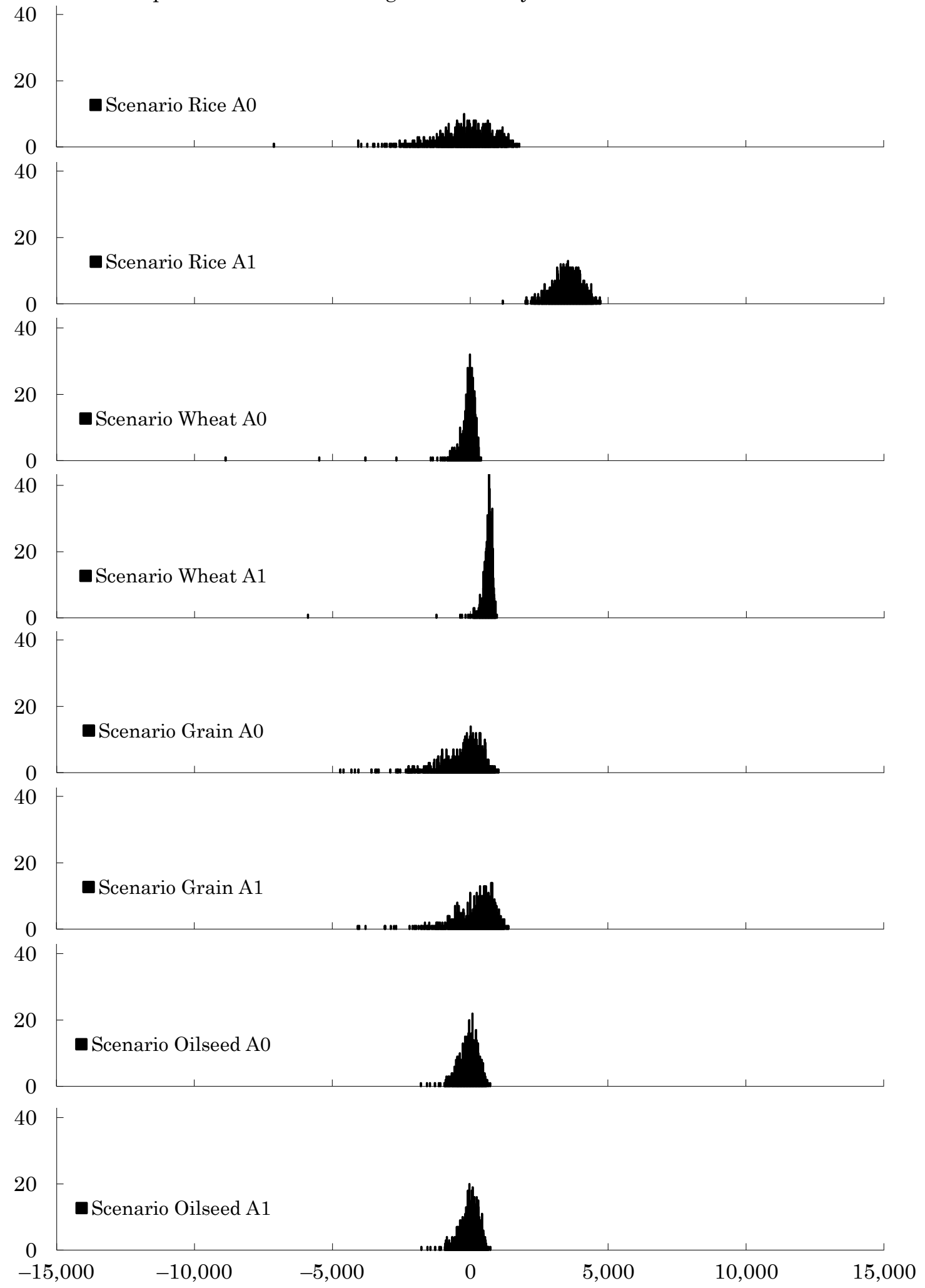


Figure A.5: Welfare Distribution with and without Trade Liberalization for All of the Four Major Crops (Elasticity of Substitution for the Composite Food=1.0) [mil. USD]

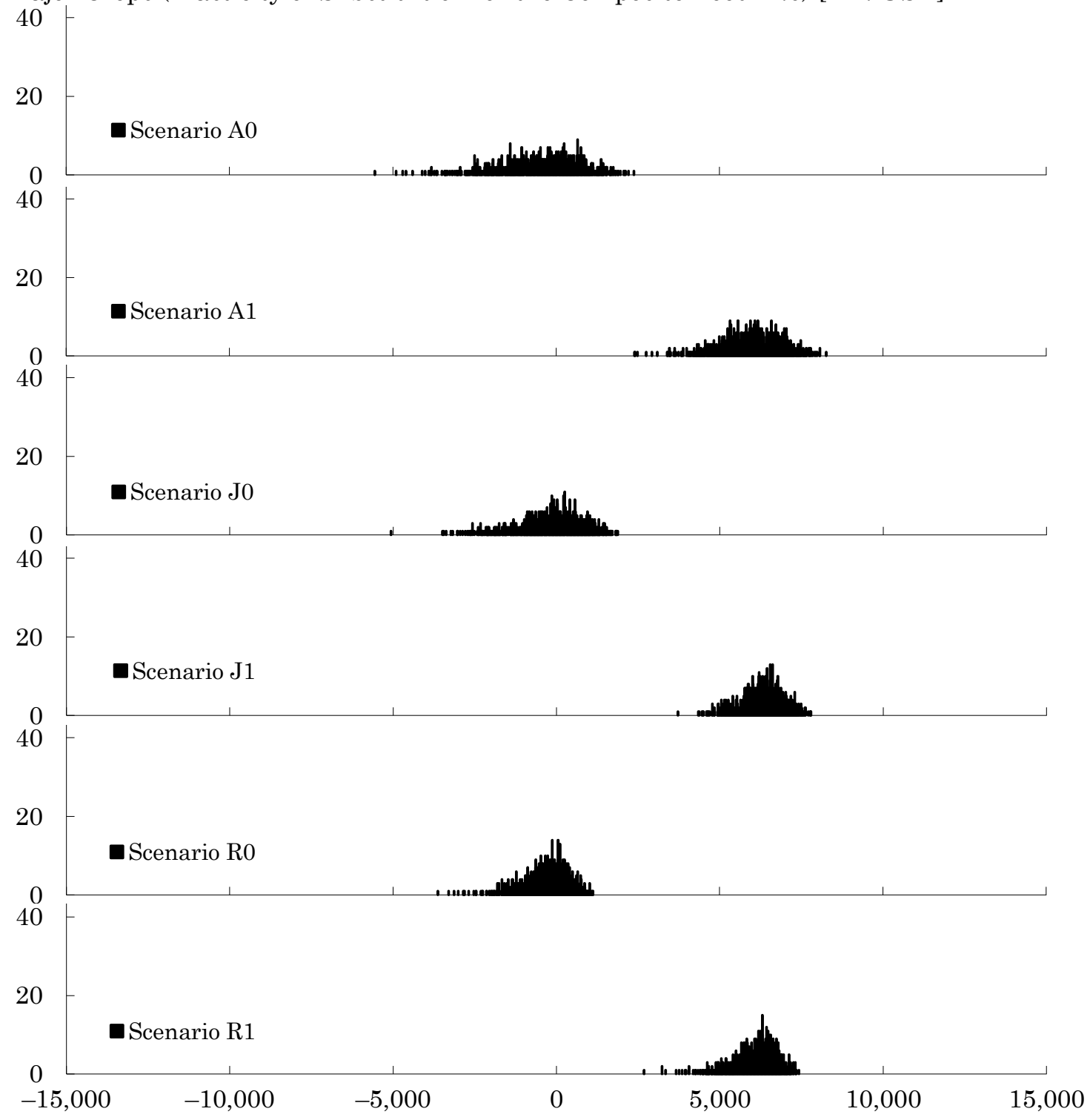


Figure A.6: Welfare Distribution with and without Trade Liberalization for the Four Individual Crops (Elasticity of Substitution for the Composite Food=1.0) [mil. USD]

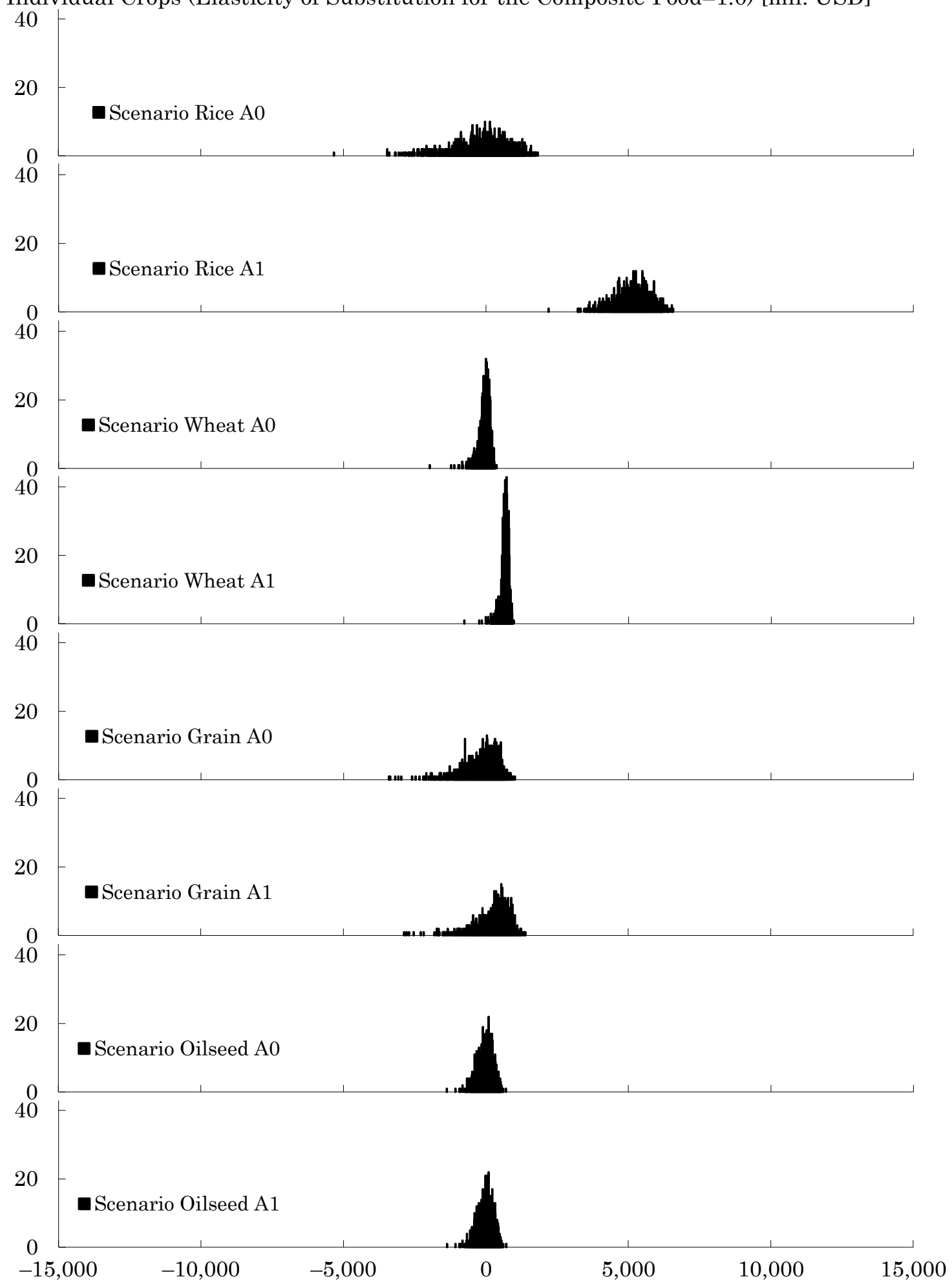


Figure A.5: Welfare Distribution with and without Trade Liberalization for All of the Four Major Crops (Elasticity of Substitution for the Composite Factor=1.0) [mil. USD]

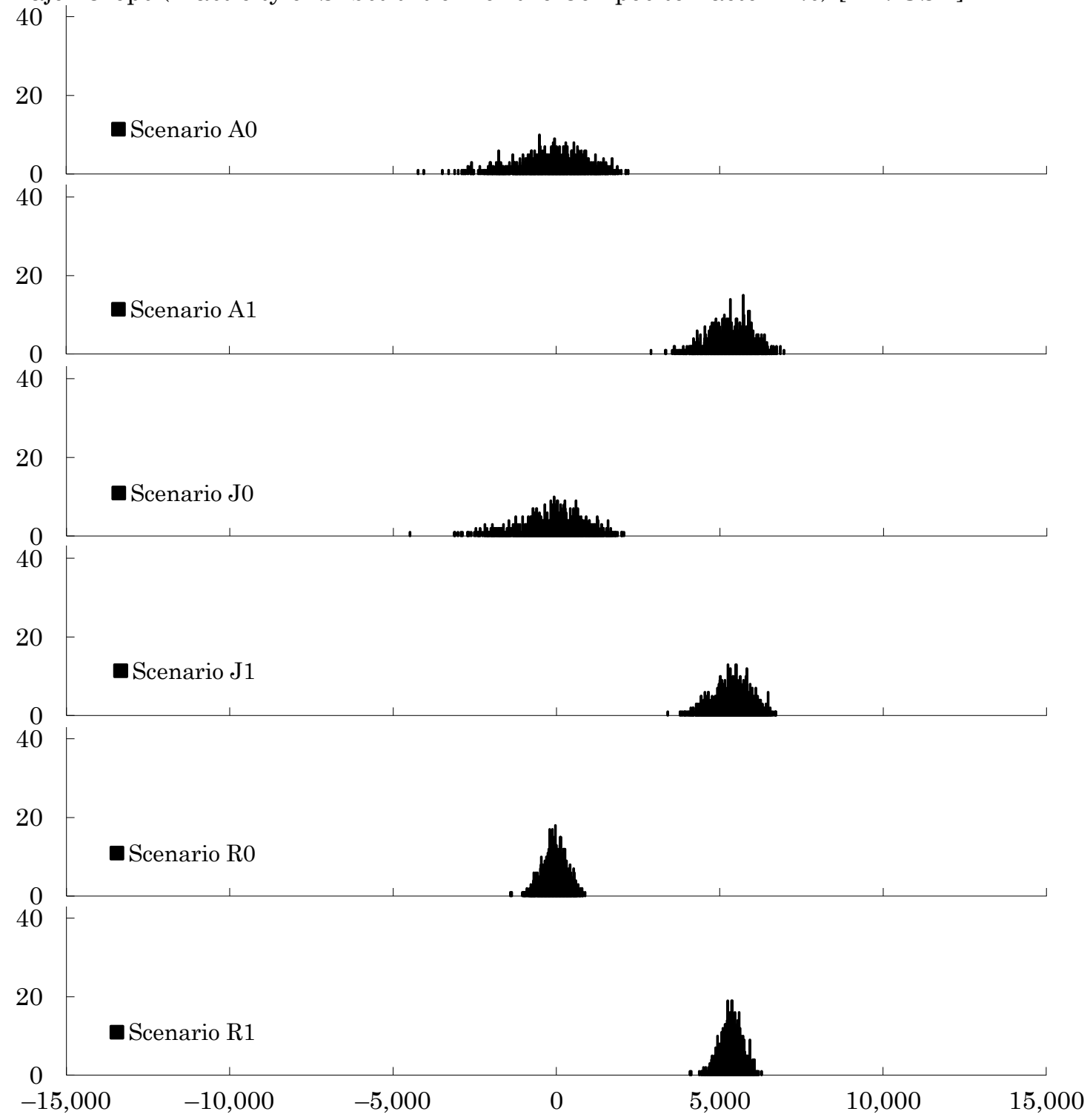


Figure A.6: Welfare Distribution with and without Trade Liberalization for the Four Individual Crops (Elasticity of Substitution for the Composite Factor=1.0) [mil. USD]

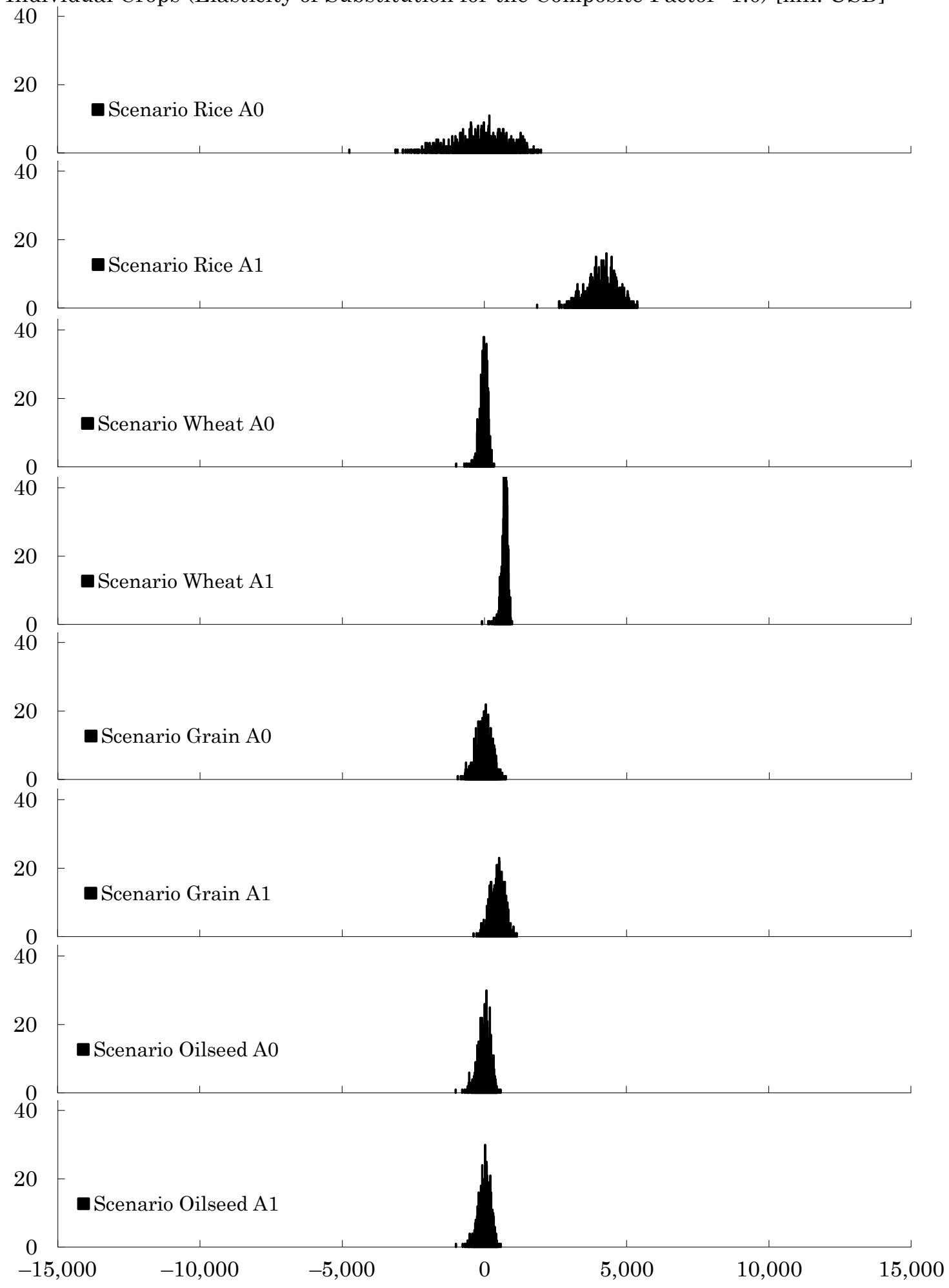




\section{A.2 Spatial Correlations of Productivity Shocks}

We assumed no spatial correlations of productivity shocks among the 10 regions in our Monte Carlo experiments. To verify the validity of this simplification, we computed correlations of the regional crop productivity variations (Table A.1). While some coefficients for grain and oilseed between adjacent regions in Asia were found to be large, exceeding, say, 0.5, we found only weak correlations between productivity shocks in adjacent regions. Of course, we can elaborate this productivity estimation part further, following, for example, Furuya and Koyama (2005) by explicitly considering precipitation and temperature in each region, which often correlate with each other globally. However, more elaborated models would generally yield smaller residuals and thus smaller variations of productivity, which are fed into the Monte Carlo experiments as shocks, than those we assumed for our original simulations (Table 2.2). This would reduce the source of concerns of the national food security and, thus, would be more likely to reinforce our conclusion further. 
Table A.1: Inter-regional Productivity Correlation Coefficients by Crop

\begin{tabular}{|c|c|c|c|c|c|c|c|c|c|}
\hline Rice & JPN & RUS & E_U & NAM & LAM & EAS & SAS & SEA & ANZ \\
\hline RUS & 0.00 & & & & & & & & \\
\hline E_U & 0.03 & -0.74 & & & & & & & \\
\hline NAM & 0.12 & -0.01 & -0.12 & & & & & & \\
\hline LAM & 0.23 & -0.22 & 0.00 & 0.08 & & & & & \\
\hline EAS & 0.28 & -0.25 & 0.33 & -0.52 & 0.33 & & & & \\
\hline SAS & -0.30 & -0.04 & -0.26 & -0.12 & -0.01 & -0.02 & & & \\
\hline SEA & -0.05 & 0.48 & -0.69 & 0.53 & -0.18 & -0.41 & 0.09 & & \\
\hline ANZ & -0.09 & -0.08 & 0.11 & -0.36 & 0.33 & 0.03 & 0.08 & -0.55 & \\
\hline ROW & -0.34 & -0.23 & -0.13 & -0.14 & 0.33 & 0.18 & 0.23 & 0.25 & -0.25 \\
\hline \multicolumn{10}{|c|}{ Wheat } \\
\hline RUS & 0.25 & & & & & & & & \\
\hline E_U & -0.19 & 0.03 & & & & & & & \\
\hline NAM & 0.02 & -0.32 & 0.45 & & & & & & \\
\hline LAM & 0.19 & -0.37 & -0.23 & 0.43 & & & & & \\
\hline EAS & -0.12 & 0.27 & 0.18 & 0.24 & 0.40 & & & & \\
\hline SAS & -0.11 & -0.20 & -0.03 & -0.24 & 0.09 & -0.35 & & & \\
\hline SEA & 0.54 & 0.38 & -0.42 & -0.19 & -0.07 & 0.06 & -0.43 & & \\
\hline ANZ & -0.35 & -0.10 & 0.14 & 0.59 & 0.18 & -0.03 & 0.00 & -0.49 & \\
\hline ROW & 0.14 & 0.67 & 0.08 & -0.32 & -0.56 & 0.02 & -0.29 & 0.42 & -0.21 \\
\hline \multicolumn{10}{|l|}{ Grain } \\
\hline RUS & 0.18 & & & & & & & & \\
\hline E_U & -0.18 & 0.03 & & & & & & & \\
\hline NAM & -0.11 & -0.20 & 0.26 & & & & & & \\
\hline LAM & -0.14 & 0.34 & -0.19 & -0.29 & & & & & \\
\hline EAS & 0.02 & -0.29 & 0.03 & 0.13 & 0.17 & & & & \\
\hline SAS & 0.18 & 0.04 & -0.26 & 0.05 & 0.68 & 0.44 & & & \\
\hline SEA & 0.41 & 0.22 & 0.00 & 0.18 & 0.46 & 0.53 & 0.76 & & \\
\hline ANZ & -0.13 & -0.06 & 0.23 & -0.08 & 0.26 & -0.24 & 0.04 & -0.03 & \\
\hline ROW & 0.24 & 0.59 & 0.42 & 0.11 & -0.04 & 0.33 & -0.08 & 0.30 & -0.27 \\
\hline \multicolumn{10}{|c|}{ Oilseed } \\
\hline RUS & -0.20 & & & & & & & & \\
\hline E_U & -0.13 & -0.08 & & & & & & & \\
\hline NAM & 0.23 & -0.05 & 0.40 & & & & & & \\
\hline LAM & 0.21 & -0.35 & -0.51 & -0.53 & & & & & \\
\hline EAS & 0.21 & -0.33 & 0.45 & 0.17 & -0.10 & & & & \\
\hline SAS & 0.18 & 0.27 & -0.08 & 0.32 & -0.25 & -0.59 & & & \\
\hline SEA & -0.10 & 0.55 & -0.09 & 0.07 & -0.63 & -0.55 & 0.53 & & \\
\hline ANZ & -0.17 & -0.04 & 0.21 & -0.18 & 0.14 & 0.07 & 0.04 & -0.29 & \\
\hline ROW & 0.15 & 0.39 & -0.22 & 0.07 & -0.07 & -0.06 & 0.05 & 0.26 & -0.28 \\
\hline
\end{tabular}

Note: Bold face indicates $|r|>0.50$. 